Alma Mater Studiorum - Università di Bologna DEPARTMENT OF ECONOMICS

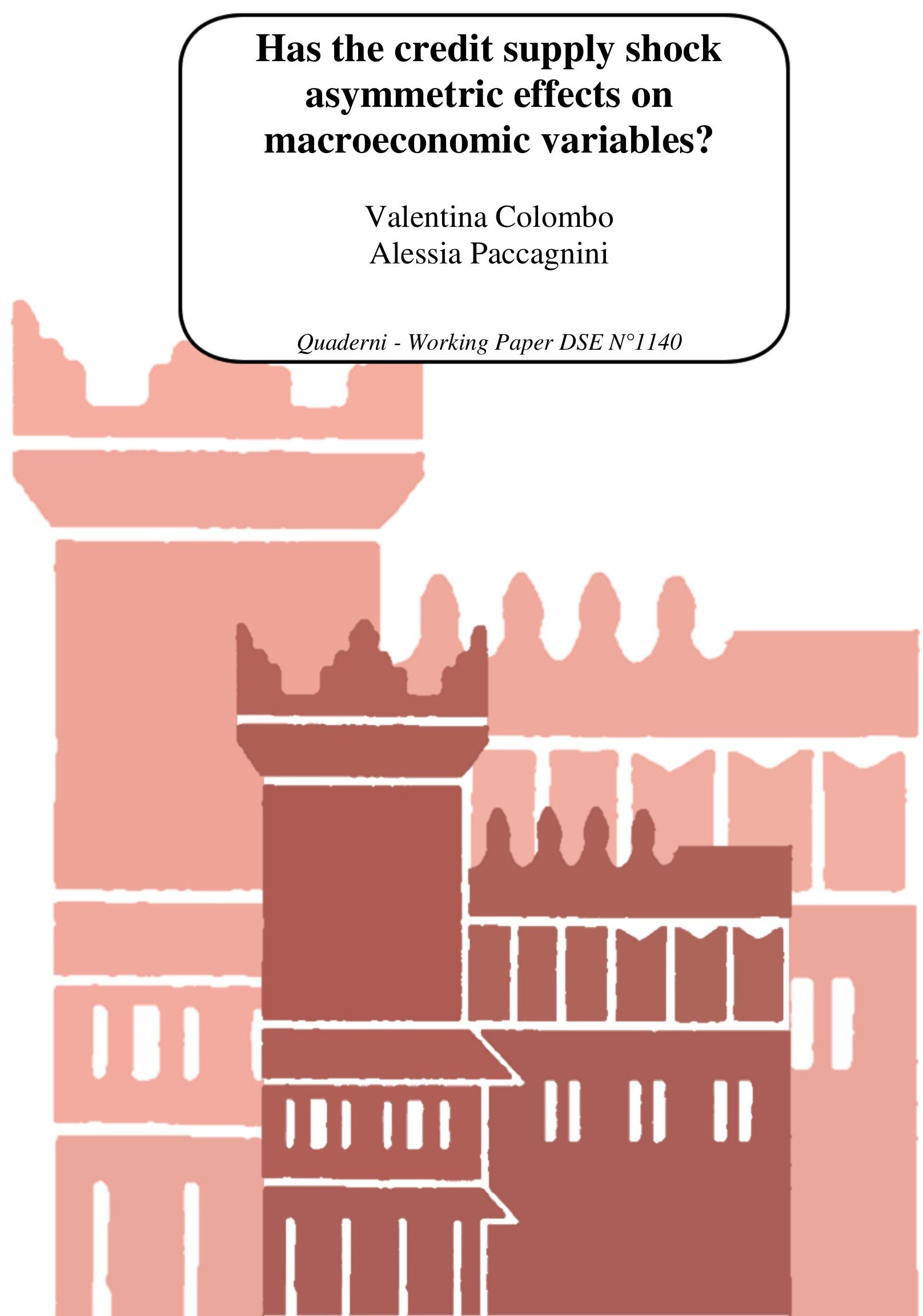




\title{
Has the credit supply shock asymmetric effects on macroeconomic variables?*
}

\author{
Valentina Colombo $o^{\dagger} \quad$ Alessia Paccagnini ${ }^{\ddagger}$
}

\begin{abstract}
We investigate the role played by the credit supply shock across the business cycle in the U.S. over the period 1973 - 2018. We estimate a nonlinear VAR including nominal, real, monetary, and financial variables. According to our results, a credit supply shock triggers asymmetric and negative effects on macroeconomic variables. We find that the state-dependent forecast error variance decomposition of industrial production, employment, and inflation due to the shock is from six to eight times larger in recessions than in normal times.
\end{abstract}

JEL classification: C32, E32, E52

Keywords: Credit supply shock, Smooth Transition VAR, Nonlinearities.

*We thank Giovanni Caggiano, Efrem Castelnuovo, Raffaele Giuliana, and Massimiliano Marzo for useful comments. All remaining errors are ours.

${ }^{\dagger}$ Department of Economics, University of Bologna. Email: valentina.colombo3@unibo.it.

${ }^{\ddagger}$ Michael Smurfit Business Graduate Business School, University College Dublin, and Center for Applied Macroeconomic Analysis. Email: alessia.paccagnini@ucd.ie. 


\section{Non - Technical Summary}

Financial shocks have been recognized as important drivers for explaining macroeconomic dynamics via the well-known financial acceleration mechanism. Since the onset of the Great Recession, the literature has renewed interest in the interaction between credit supply shock and macroeconomic activities. Most empirical contributions study this interaction in a linear set-up. They find that credit supply shocks have contractionary effects on macroeconomic variables. However, empirical evidences highlight that the macro-financial linkages may be nonlinear. Such nonlinear relation has been scrutinized in studying the role of credit markets in the transmission mechanisms of economic shocks rather than studying the asymmetric effect of a credit supply shock per se.

We contribute to the state of art studying whether credit supply shocks affect asymmetrically macroeconomic variables over the business cycle. We model variables with a Smooth Transition VAR (STVAR) in which an exogenous credit supply shock is allowed to affect macroeconomic variables conditional on the states of the economy ("Recessionary Periods" vs "Normal Times"). The credit supply shock is identified by appealing to the excess bond premium indicator (EBP).

Fitting the post-WWII U.S. monthly data in a Smooth Transition VAR, we find systematic asymmetries across business cycle phases in the response to a credit supply shock. We conjecture that the financial-accelerator mechanism may play a larger role in severely deepen the macroeconomic activity, depending on which phase of the business cycle the economy is when the credit shock occurs. Findings reveal that during normal times, the EBP shock impacts negatively only industrial production. Differently, there is an amplification effect when the economy is already in recessions: an exogenous contraction in the supply of credit affects negatively not only industrial production, but also inflation and employment. As our results suggest, negative business cycle effects due to financial shocks get magnified when the economy is already in a bust phase. Our impulse responses confirm the role of credit supply shocks in driving macroeconomic fluctuation quantifying a more than double drop in the macroeconomic variables in recessions than in normal times. Moreover, we show that contractions in the supply of credit in recessions (but not in normal times) work as a demand shock, in the sense of being associated with a fall in output and prices at the same time.

Interesting, the shock seems to explain a fraction of the variance of real variables (industrial production and employment) and inflation that is from six to eight times larger in recessions than in normal times. Moreover, the credit supply shock appears to be the first source of fluctuation of employment in recessions but not in normal times on which the contribution of macroeconomic shocks prevail. The EBP is more important than monetary shocks in explaining macroeconomic fluctuation in recessions. 


\section{Introduction}

Financial shocks have been recognized as important drivers for explaining macroeconomic dynamics via the well-known financial acceleration mechanism (see e.g., Bernanke and Blinder, 1988; Gilchrist and Zakrajšsek, 2012). Since the onset of the Great Recession, the literature has renewed interest in the interaction between credit supply shock and macroeconomic activities (Gertler and Gilchrist, 2018). Most empirical contributions study this interaction in a linear set-up (see e.g., Gilchrist and Zakrajšek, 2012; LópezSalido, Stein, and Zakrajšek, 2017; Caldara, Fuentes-Albero, Gilchrist, and Zakrajšek, 2016; Faust, Gilchrist, Wright, and Zakrajšek, 2013; Stock and Watson, 2012). They find that credit supply shocks have contractionary effects on macroeconomic variables. However, empirical evidences highlight that the macro-financial linkages may be nonlinear.

Such nonlinear relation has been scrutinized in studying the role of credit markets in the transmission mechanisms of economic shocks (see e.g., Alessandri and Muntaz, 2019; Rüth, 2017; Alessandri, Conti, and Venditti, 2017) rather than studying the asymmetric effect of a credit supply shock per se. As for the literature dealing with asymmetries of credit supply shocks, Barnichon, Matthes, and Ziegenbein (2019) find that the effects of such shock depend on its size and sign. It highlights that some asymmetries may be at work.

Do credit supply shocks affect asymmetrically macroeconomic variables over the business cycle? To answer our question, we model variables with a Smooth Transition VAR (STVAR) in which an exogenous credit supply shock is allowed to affect macroeconomic variables conditional on the states of the economy ("Recessionary Periods" vs "Normal Times"). The credit supply shock is identified by appealing to the excess bond premium indicator (EBP) constructed by Gilchrist and Zakrajšek (2012) and plotted in figure 1. Fitting the post-WWII U.S. monthly data in a Smooth Transition VAR, we find the answer to our question to be positive: (i) a one standard deviation shock leads to systematic asymmetries across business cycle phases in the responses to a credit supply shock; (ii) the variance of real and nominal variables explained by the shock is from six to eight times larger in recessionary periods than in normal times; (iii) the shock triggers effects of "demand-type" in recessions but not in normal times.

Our paper is structured as follows. Section 2 describes the data and the identification strategy implemented in the Smooth Transition VAR. Section 3 discusses the results. Section 4 concludes.

\section{Data and Methodology}

We study the asymmetric effects of a credit supply shock relying on a Smooth Transition VAR (STVAR) which is defined as follows: 


$$
\begin{aligned}
X_{t} & =F\left(z_{t-1}\right) \Pi_{R}(L) X_{t}+\left(1-F\left(z_{t-1}\right)\right) \Pi_{N T}(L) X_{t}+\varepsilon_{t}, \\
\varepsilon_{t} & \sim N\left(0, \Omega_{t}\right), \\
\Omega_{t} & =F\left(z_{t}\right) \Omega_{R}+\left(1-F\left(z_{t}\right)\right) \Omega_{N T}, \\
F\left(z_{t}\right) & =\exp \left(-\gamma z_{t}\right) /\left(1+\exp \left(-\gamma z_{t}\right)\right), \gamma>0, z_{t} \sim N(0,1) .
\end{aligned}
$$

where $X_{t}$ is a set of endogenous variables, $\Pi(L)_{R}$ and $\Pi(L)_{N T}$ are the polynomial matrices capturing the dynamics of the system during recession and normal times, respectively. The vector of reduced-form residuals $\left(\varepsilon_{t}\right)$ has zero-mean and heteroskedastic variance-covariance matrix $\Omega_{t}$. The function $F\left(z_{t-1}\right)$ is the logistic function capturing the probability of being in a recession. It depends on the state variable $z_{t}$ and on the smoothness parameter $\gamma$ which dictates how smooth is the transition from one regime to another (i.e. lower value a higher smooth, higher value lower smooth).

The transition variable $z_{t}$ is the standardized backward-looking 12-month moving average growth rate of industrial production. As in Auerbach and Gorodnichenko (2012) and Caggiano, Castelnuovo, Colombo, and Nodari (2015), we calibrate the smoothness parameter $\gamma$ to match the probability of being in recessions as identified by the NBER business cycle dates ( $15 \%$ in our sample). The recessionary phase is defined as a period in which $\operatorname{Pr}\left(F\left(z_{t}\right) \geqslant 0.85\right) \approx 15 \%$. It means that the economy spends about $15 \%$ of time in recession and $85 \%$ in normal times. This implies setting $\gamma=2.3 .^{1}$.

Following Caldara, Fuentes-Albero, Gilchrist, and Zakrajšek (2016), $X_{t}$ includes (from the top to the bottom): (i) the CPI inflation; (ii) the manufacturing industrial production growth; (iii) the employment rate; (iv) the EBP; (v) the cumulated value-weighted total stock market (log) return; (vi) the nominal 10-year Treasury yield, and (vii) the nominal 1-year Treasury yield ${ }^{2}$.

The EBP captures the "risk-bearing capacity" of the financial intermediate sector. Based on market prices of individual corporate bonds traded in the secondary market, Gilchrist and Zakrajšek (2012) construct a credit spread of the U.S. nonfinancial corporations over Treasury bond yields with identical cash flow and maturity characteristics. Then, they decompose such spread into a component reflecting the countercyclical move-

\footnotetext{
${ }^{1}$ The choice is consistent with the threshold value of $\bar{z}=-0.95 \%$ discriminating recessions and normal times. In particular, if the realizations of the standardized transition variable $z_{t}$ is lower (higher) than the threshold value $\bar{z}$, it will be associated with recessions (normal times). The transition variable $z_{t}$ has been standardized to be comparable to those employed in the literature. Following Auerbach and Gorodnichenko (2012), we rely on the lagged value of $\mathrm{z}$ in Equation (1) to avoid contemporaneous feedbacks from the shock into the state of the economy. The online appendix, Section A, reports the figure of the $F\left(z_{t}\right)$.

${ }^{2}$ To overcome the fact that the Federal Funds rate was at the zero lower bound, we rely on the one-year Treasury maturity since it accounts for term structure effects due, for instance, to forward guidance (see e.g., Gertler and Karadi, 2015; Alessandri, Conti, and Venditti, 2017)
} 
ment in default risks and a residual, the so-call Excess Bond Premium (EBP) which is linked to the financial conditions of the issuer. Thus, the EBP captures the extra return that investors demand to hold corporate bonds over and above the compensation for the credit risk (credit market sentiment).

Figure 1: Excess Bond Premium vs Business cycle

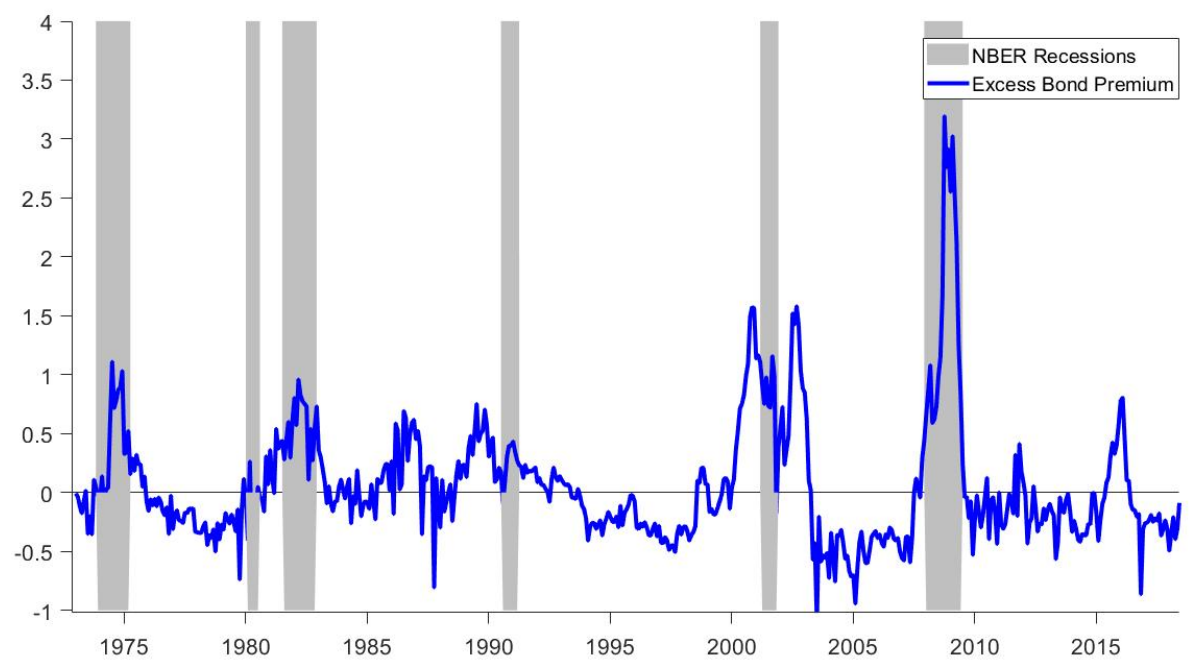

Notes: The shaded area indicate the U.S. recessionary phases (1973:M1-2018:M12), whereas the blue line refers to the Excess Bond Premium indicator by Gilchrist and Zakrajšek (2012).

The credit supply shock is identified via the Cholesky-decomposition with the assumptions provided by Gilchrist and Zakrajšek (2012). In other words, the slow-moving variables (CPI, Industrial Production, and Employment) are ordered before the shock, whereas the fast-moving variables (risk-stock return and free rates) are ordered after that. It means that we "purge" our credit supply indicator from the contemporaneous movements of our macroeconomic variables, therefore sharpening the identification of the credit supply shock. Hence, an unexpected change in EBP will be orthogonal to the business cycle at time $t$.

We estimate the STVAR in (1) via the Markov-Chain Monte Carlo simulation (Chernozhukov and Hong, 2014) and we model the endogeneity of the transition from one state to another one after a credit supply shock occurs computing the Generalized Impulse Response Functions (GIRFs) proposed by Koop, Pesaran, and Potter (1996). Since the GIRFs depend on the initial condition, we study the evolution of the GIRFs over histories (i.e., recession versus normal times).

Our data are monthly and span the period 1973M1-2018M12. The beginning of the period depends on the availability of the EBP indicator. We estimate a nonlinear 
VAR including five lags, as indicated by the Akaike information criterion. The data are retrieved from the Federal Reserve Bank of St. Louis, apart from the EBP and the stock return downloaded by the Board of Governors of the Federal Reserve System's website and the Center for Research in Security Prices (CRSP), respectively.

Before estimating the STVAR in (1), we test the linearity of our VAR and the LM test suggests a strong rejection of the linearity for the system as a whole in favor of a particular nonlinear model, the STVAR. ${ }^{3}$

\section{Results}

Figure 2 depicts the GIRFs of an EBP shock that is orthogonal to the state of the economy. An unexpected increase of one standard deviation in EBP generates asymmetric effects on the economy and financial markets. A higher EBP triggers negative macroeconomic fluctuations both in recessions (first column of figures 2) and in normal times (second column). However, the responses of our variables are larger (in absolute value) and more persistent in recessions than in normal times. Indeed, the shock causes a trough response of industrial production that is more than twice larger in recessions than in normal times $(-1.3 \%$ versus $-0.6 \%)$. The industrial production goes back to its steady-state two years after the shock occurs in normal times but it takes one year more to turn to its pre-shock level during a recessionary period. Meanwhile, the fall in employment is four times larger in recessions than in normal times $(-1.2 \%$ versus $-0.3 \%)$. The deflationary impact and the reduction in employment of the shock are statistically significant only during recessionary periods but not in normal times. The Federal Reserve lowers the interest rate in both states by adopting an expansionary monetary policy. Despite an easing monetary policy environment, the stock market returns drop.

The statistical test based on the empirical density of the difference between the reactions of macroeconomic and financial variables in recessions and normal times (third column of figure 2) confirms that quantitatively the responses are different across regimes from a statistical point of view.

Overall, our results highlight the systematic asymmetries across business cycle phases in the response to a credit supply shock. A possible interpretation of our findings is provided by Gilchrist and Zakrajšek (2011). Working with a DSGE framework, they show that an adverse financial shock conceptually in line with an increase in EBP reduces the risk-bearing capacity of the financial sector and, consequently, the supply of credit available to potential borrowers. Such a reduction in credit supply is associated to a drop in firms' cash flows and in the value of asset prices, and a slowdown in economic activity. We conjecture this financial-accelerator mechanism may play a larger role in severely

\footnotetext{
${ }^{3}$ See Section C, D and E of the online Appendix for further details related to the linearity test, the STVAR estimation and the computation of the GIRFs.
} 
deepen the macroeconomic activity, depending on which phase of the business cycle the economy is when the credit shock occurs. Findings reveal that during normal times, the EBP shock impacts negatively only industrial production. Differently, there is an amplification effect when the economy is already in recessions: an exogenous contraction in the supply of credit affects negatively not only industrial production, but also inflation and employment. As our results suggest, negative business cycle effects due to financial shocks get magnified when the economy is already in a bust phase.

Figure 2: Generalised impulse responses (GIRFs) to credit supply shocks
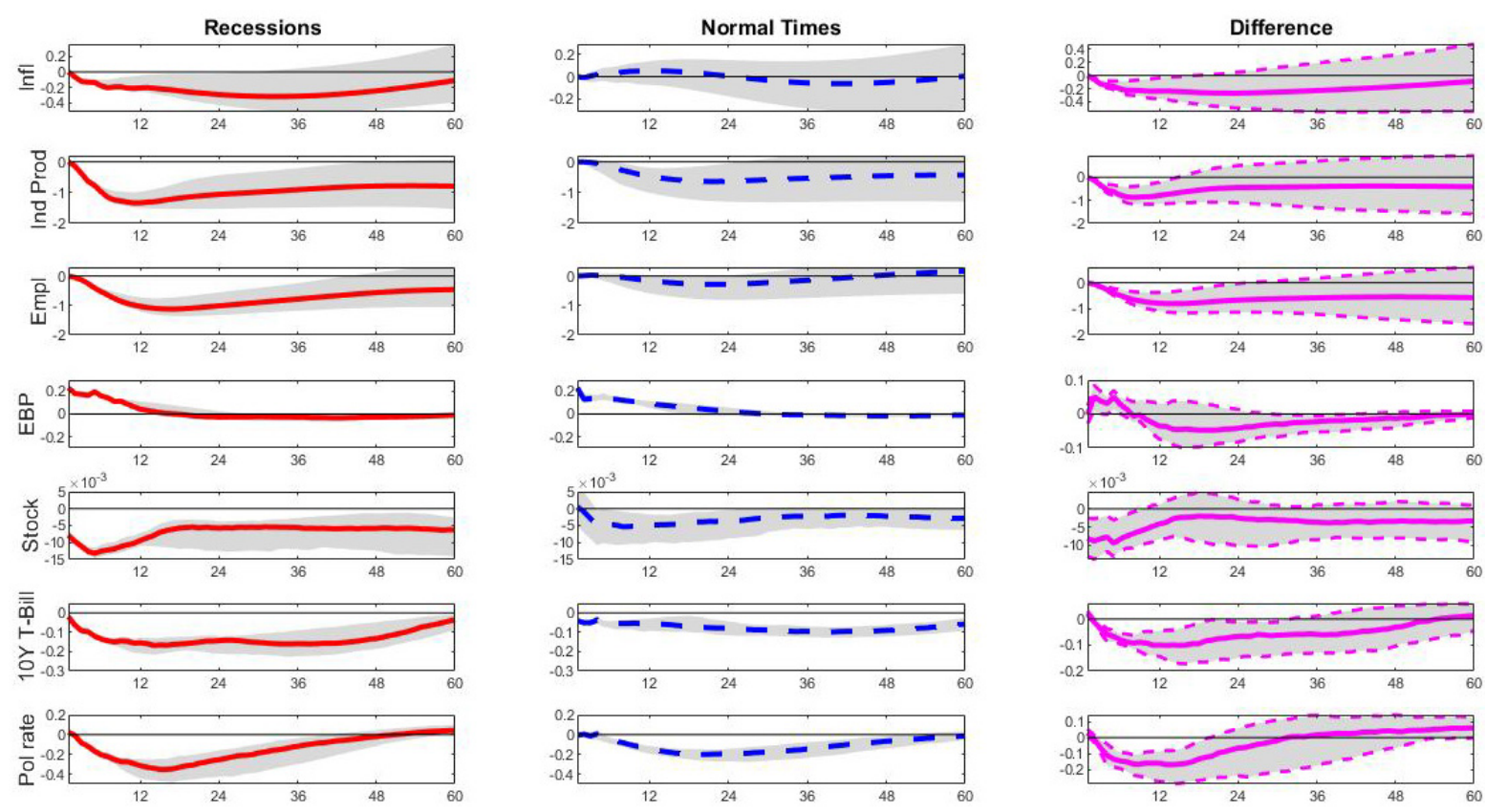

Notes: The figure reports the generalized impulse responses (GIRFs) to an unanticipated U.S. credit supply shock in recessions (first column), in normal times (second columns), and the median realizations of the differences between generalized impulse responses in recessions and normal times (third column). The red and blue lines denote the median GIRFs in recessions and in normal times, respectively. The magenta lines refer to the median of the difference realizations between the two states of the world. Shaded bands denote confidence intervals at $68 \%$ levels. The responses of inflation, industrial production ad employment are accumulated. The horizontal axis identifies months, whereas the vertical axis is expressed in percentage points.

Relying on time-varying parameters VAR, Gambetti and Musso (2019) find that credit supply shocks are particularly important during recessions. Our impulse responses confirm the role of credit supply shocks in driving macroeconomic fluctuation quantifying a more than double drop in the macroeconomic variables in recessions than in normal times. Moreover, we show that contractions in the supply of credit in recessions (but not in normal times) work as a demand shock, in the sense of being associated with a fall in 
output and prices at the same time. ${ }^{4}$

How important is a credit supply shock in driving economic dynamics? Table 1 reports the state-dependent 12-months ahead forecast error variance decomposition (FEVD) for each variable of interest computed à la Lanne and Nyberg (2016).

Forecast Error Variance Decomposition

\begin{tabular}{|c|c|c|c|c|c|c|c|}
\hline & Recession & & & & & & \\
\hline Shock/Variable & $\pi$ & $\mathrm{y}$ & $\mathrm{e}$ & $\mathrm{EBP}$ & stock & $i_{10 y}$ & $\mathrm{i}$ \\
\hline$\tilde{\epsilon}^{\pi}$ & 60.8 & 11.3 & 5.6 & 5.3 & 0.4 & 5.1 & 2.7 \\
\hline$\tilde{\epsilon}^{y}+\tilde{\epsilon}^{e}$ & 14.7 & 42.7 & 22.9 & 4.4 & 9.2 & 10.5 & 16.5 \\
\hline$\tilde{\epsilon}^{E B P}$ & 10.8 & 27.3 & 41.1 & 79.9 & 32.3 & 16.3 & 18.4 \\
\hline$\tilde{\epsilon}^{s t o c k}$ & 3.25 & 8.6 & 16.2 & 8.8 & 55.3 & 20.7 & 30.4 \\
\hline \multirow[t]{2}{*}{$\tilde{\epsilon}^{i_{10 y}}+\tilde{\epsilon}^{i}$} & 10.8 & 9.9 & 14.2 & 1.5 & 2.8 & 47.5 & 32.4 \\
\hline & Normal times & & & & & & \\
\hline$\tilde{\epsilon}^{\pi}$ & 87.5 & 2.7 & 2.3 & 2.5 & 7.1 & 4.7 & 4.5 \\
\hline$\tilde{\epsilon}^{y}+\tilde{\epsilon}^{e}$ & 3 & 86.5 & 79.2 & 3.3 & 1.3 & 8.9 & 13.3 \\
\hline$\tilde{\epsilon}^{E B P}$ & 1.3 & 4.1 & 5 & 87 & 5.9 & 2 & 2.9 \\
\hline$\tilde{\epsilon}^{\text {stock }}$ & 2.1 & 3.7 & 6.5 & 6 & 82.6 & 5.83 & 7.8 \\
\hline$\tilde{\epsilon}^{i_{10 y}}+\tilde{\epsilon}^{i}$ & 6.1 & 2.9 & 7 & 1.2 & 3.1 & 78.8 & 71.4 \\
\hline
\end{tabular}

Table 1: Fractions of variances of each variable explained by the shocks reported on the column and in percentage. $\pi$ is the inflation rate; $y$ and $e$ are the rate of growth of industrial production and employment, respectively. EBP stands for excess bond premium, while stock refers to the stock return. $i_{10 y}$ denotes the $10-$ year Treasury Bill and $i$ is the 1 - year Treasury Bill. The shocks indicated in the first column are the shocks to: inflation $\left(\tilde{\epsilon}^{\pi}\right)$, industrial production $\left(\tilde{\epsilon}^{y}\right)$ and employment $\left(\tilde{\epsilon}^{e}\right)$, the excess bond premium $\left(\tilde{\epsilon}^{E B P}\right)$, stock return $\left(\tilde{\epsilon}^{\text {stock }}\right)$ and long and short interest rate $\left(\tilde{\epsilon}^{i_{10 y}}\right.$ and $\left.\tilde{\epsilon}^{i}\right)$. The variance decomposition is reported 12 months ahead.

Interesting, the shock seems to explain a fraction of the variance of real variables (industrial production and employment) and inflation that is from six to eight times larger in recessions than in normal times. Moreover, the credit supply shock appears to be the first source of fluctuation of employment in recessions but not in normal times on which the contribution of macroeconomic shocks prevail. This result is in line with Caggiano, Castelnuovo, and Figueres (2017) which found asymmetric reactions of (un)employment across the business cycle. Moreover, the change in the short and long interest rates is

\footnotetext{
${ }^{4}$ Our results are robust to: (i) (re)calibrate the probability of being in recessions equal to $10 \%(\gamma=1.6)$ and to 20\% $(\gamma=3.2)$; (ii) (re-)estimate the model with one lag and a $z_{t}$ defined as standardized backward-looking 6-month moving average growth rate of industrial production; (iii) the inclusion of a factor extracted from macroeconomic variables of a large panel dataset of the U.S. macro and financial variables as discussed in McCracken and $\mathrm{Ng}$ (2016) to improve the identification of the shock; (iv) alternative indicators of credit supply shock such as the Moody's $B A A-A A A$, the GZ corporate bond credit spread (Gilchrist and Zakrajšek, 2012), and Chicago Fed's National Financial Conditions Index; (iv) focus on a small sample size excluding from our sample the Great Recession (1973:M1-2007:M11). We report the results of the above exercises on the online Appendix, Section B.
} 
six and eight times, respectively, larger in recessions than in normal times. The EBP is more important than monetary shocks in explaining macroeconomic fluctuation in recessions. The macroeconomic shocks appear to be more important than the monetary ones in explaining the fluctuation of macroeconomic activity. Conversely, the contribution of monetary policy shocks tend to be more important for the fluctuation of monetary variables. ${ }^{5}$

\section{Conclusion}

We investigate to what extent a U.S. credit supply shock has asymmetric effects on inflation, industrial production, and employment. The estimated Smooth Transition VAR provides evidence of a systematic asymmetry in the impact of credit supply shocks between recessionary and normal times. The contribution of an exogenous variation of the excess bond premium indicator is from six to eight times larger in recessions than in normal times.

\section{References}

Alessandri, P., A.M. Conti, and F. Venditti (2017). "The Financial Stability Dark Side of Monetary Policy". Economic working papers, Bank of Italy, Economic Research and International Relations Area, 1121.

Alessandri, P. and H. Muntaz (2019). "Financial Regimes and Uncertainty Shocks". Journal of Monetary Economics, 101, pp. 31-46.

Auerbach, A. and Y. Gorodnichenko (2012). "Measuring the Output Responses to Fiscal Policy". American Economic Journal: Economic Policy 54(2), pp. 1-27.

Barnichon, R., C. Matthes, and A. Ziegenbein (2019). "Are the Effects of Financial Market Disruptions Big or Small?" mimeo.

Bernanke, B.S. and A. Blinder (1988). "Credit, Money and Aggregate Demand". American Economic Review, 78, pp. 435-439.

Caggiano, G., E. Castelnuovo, V. Colombo, and G. Nodari (2015). "Estimating Fiscal Multipliers: News From a Nonlinear World". Economic Journal 125(584), pp. 746776.

Caggiano, G., E. Castelnuovo, and J.M. Figueres (2017). "Economic Policy Uncertainty and Unemployment in the United States: A Nonlinear Approach". Economics Letters, 151, pp. 31-34.

\footnotetext{
${ }^{5}$ Such results are robust to the state-dependent FEVD obtained conditional on a Factor Augmented Smooth Transition VAR exercise. Results available upon request.
} 
Caldara, D., C. Fuentes-Albero, S. Gilchrist, and E. Zakrajšek (2016). "The Macroeconomic Impact of Financial and Uncertainty Shocks". European Economic Review, 88(C), pp. 185-207.

Chernozhukov, V. and H. Hong (2014). "An MCMC Approach to Classical Estimation". Journal of Econometrics 115(2), pp. 293-346.

Faust, J., S. Gilchrist, J. H. Wright, and E. Zakrajšek (2013). "Credit Spreads as Preditors of Real-Time Economic Activity: a Bayesian Model-Averaging Approach". Review of Economics and Statistics, 95, pp. 1501-1519.

Gambetti, L. and A. Musso (2019). "Loan Supply Shocks and the Business Cycle". Journal of Applied Econometrics, 32(4), pp. 764-782.

Gertler, M. and S. Gilchrist (2018). "What Happened: Financial Factors in the Great Recession". Journal of Economic Perspectives, 32(3), pp. 3-30.

Gertler, M. and P. Karadi (2015). "Monetary Policy Surprice, Credit Costs, and Economic Activity". American Economic Journal: Macroeconomics, 7(1), pp. 44-76.

Gilchrist, S. and E. Zakrajšek (2011). "Monetary Policy and Credit Supply Shocks." IMF Economic Review 59(2), 59(2), pp. 195-232.

Gilchrist, S. and E. Zakrajšek (2012). "Credit Spreads and Business Cycle Fluctuations". Econometrica, 102(4), pp. 1692-1720.

Koop, G., M. Pesaran, and S. Potter (1996). "Impulse Response Analysis in Nonlinear Multivariate Models". Journal of Econometrics, 74(1), pp. 119-148.

Lanne, M. and H. Nyberg (2016). "Generalized Forecast Error Variance Decomposition for Linear and Nonlinear Multivariate Models". Oxford Bulletin of Economics and Statistics, 78(4), pp. 443-603.

López-Salido, D., J.S. Stein, and E. Zakrajšek (2017). "Credit-Market Sentiment and the Business Cycle". The Quarterly Journal of Economics, 132(3), pp. 1373-1426.

McCracken, M.W. and Ng (2016). "Fred-MD: A Monthly Database for Macroeconomic research". Journal of Business and Economic Statistics, 34(4), pp. 574-589.

Rüth, S.K. (2017). "State-Dependent Monetary Policy Transmission and Financial Market Tensions". Economics Letters, 157, pp. 56-61.

Stock, J.H. and M.W. Watson (2012). "Disentangling the Channels of the 2007-2009 Recession". Brookings Papers on Economic Activity, Spring 2012, pp. 81-135. 


\section{Technical Appendix}

This Technical Appendix reports the figure of the transition function, the robustness checks, the statistical evidence in favor of a nonlinear relationship between the endogenous variables included in the STVAR, the estimation of the non-linear VARs, the computation of the Generalised Impulse Responses. The technical sections are partially drawn on Caggiano, Castelnuovo, Colombo, and Nodari (2015) Appendix.

\section{A Appendix: Transition Function}

Figure A.1: Transition Function vs Business cycle

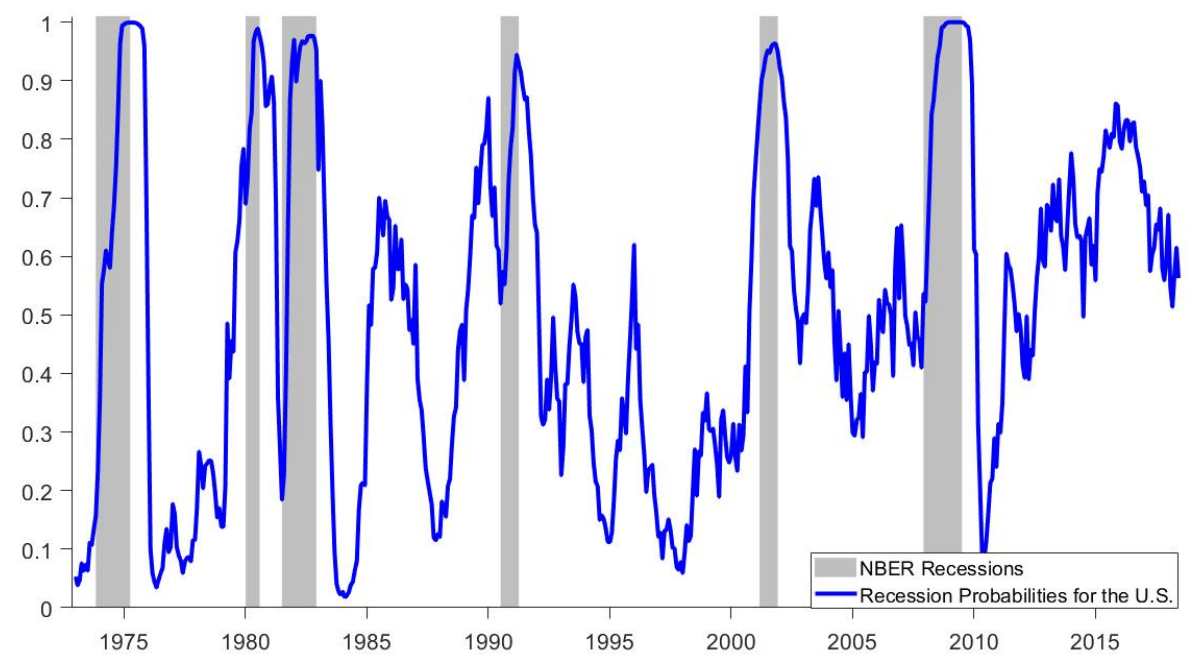

Notes: Recession Probabilities for the U.S. The shaded area indicate the U.S. recessionary phases (1973:M1-2018:M12), whereas the blue line refers to the moving average over 12 months of the industrial production growth rate.

\section{B Appendix: Robustness Checks}

Figure B.1 plots the density of the differences per industrial production, employment and inflation between recessions and normal times obtained by the battery of exercises we run to assess the robustness of our findings.

Smoothness parameter. We calibrate the smoothness parameter to match the frequencies of the U.S. recessions obtained as identified by the NBER business cycle dates (15\% in our sample). To check the sensitivity of our results to the alternative calibrations of the smoothness parameter, we (re)calibrate $\gamma$ in order to include in our sample a number of recessions ranging from $10 \%$ to $20 \%$. The probability of $10 \%$ refers to the minimum amount of observations each regime should contain (Hansen, 1999). The calibration implies a value of $\gamma=1.6$ or $\gamma=3.2$ to capture the probability of being 
in recessions equal to $10 \%$ to $20 \%$, respectively. Our results are robust to alternative calibrations of parameters.

Lag specification and transition variable. We estimate a nonlinear VAR including five lags, as indicated by the Akaike information criterion. Moreover, rely on a transition function $z_{t}$ defined as a standardized backward-looking 12-month moving average growth rate of industrial production. We modify this specification choice by relying on the lag length $\mathrm{L}=1$ and a state indicator, $z_{t}$, that include six-term moving average of the monthly growth rate of industrial production Our results are consistent with the benchmark specification.

Factor STVAR. The credit supply shock is identified via the Cholesky-decomposition with the assumptions provided by Gilchrist and Zakrajšek (2012). In particular, we set the credit supply indicator after inflation variable and the real ones. It means that we "purge" our indicator from the contemporaneous movements of our macroeconomic variables, therefore sharpening the identification of credit supply shocks. To improve the identification of the shock, we extract a factor from the macroeconomic variables of a large panel dataset of the U.S. macro and financial variables as discussed in McCracken and $\mathrm{Ng}$ (2016). We place such factor first in the vector $X_{t}$ to ensure that credit supply shock is purged from the information content of the factor. Our results are robust to such exercise.

Alternative credit supply indicators. We proxy credit supply shock trough the Excess Bond Premium (EBP) provided by Gilchrist and Zakrajšek (2012). We repeat our exercise replacing the EBP measure with alternative indicators commonly used to proxy credit supply shock: the difference between yields on BAA bonds and AAA ones computed by Moody's; the GZ corporate bond credit spread (Gilchrist and Zakrajšek, 2012) from which is extracted the EBP indicator; the FCI that is the Chicago Fed National Financial Conditions Index. Our results are consistent with the benchmark findings.

Sample size. The baseline STVAR model is estimated on the sample from 1973M1 to 2018M12. Our findings show asymmetric effects of credit supply shocks conditional on the state of the economy. Such results may be driven by the inclusion of the Great Recession period in our sample. We estimate again our model excluding from vector $X_{t}$ such period and focusing on a sample spanning from 1973M1 to 2007M11. Of course, the reaction of the macroeconomic aggregates is weaker, but our exercise confirms the nonlinearity of credit supply shock effects.

The figure B.1 confirms that our impulse responses are statistically different between the two regimes. 
Figure B.1: GIRFs
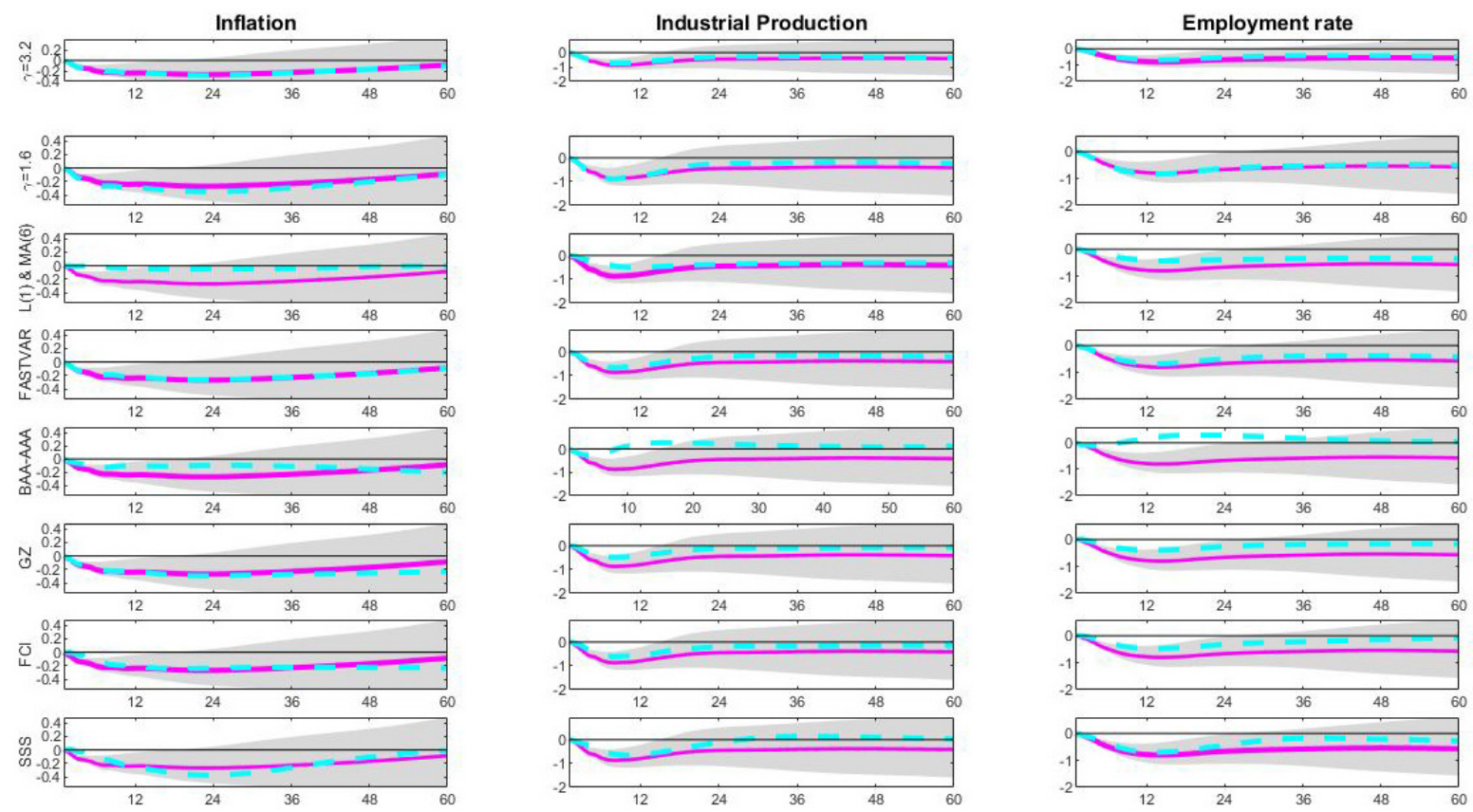

Notes: The figure reports the median realizations of the differences between generalized impulse responses in recessions and normal times to a one-standard deviation shock for inflation, industrial producttion and employment. Each row refers to an alternative specification of our baseline. For each specification the figure shows the median of the difference from the baseline specification (magenta lines) and its confidence intervals at $68 \%$ levels (shaded bands) against the median realizations of the differences from the alternative specification. From the top to the bottom: (i) $\gamma=3.2$ and $\gamma=1.6$ refer to the probability of being in recessions equal to $20 \%$ and $10 \%$, respectively (rows 1,2); model with one lag and transition variable defined as the 6-month moving average growth rate of industrial production (row 3); the inclusion of a macroeconomic factor McCracken and $\mathrm{Ng}$ (2016) to improve the identification of the shock (row 4); alternative indicators of credit supply shock such as the Moody's $B A A-A A A$ (row 5), the GZ corporate bond credit spread as in Gilchrist and Zakrajšek (2012) (row six), and the Chicago Financial Condition Index one (row seven); in last row we focus one a small sample size excluding from our sample the Great Recession (1973: M1 - $2007: M 11)$.

\section{Appendix: Linearity Test}

We test linearity versus non-linearity applying the Teräsvirta and Yang (2014) test for Smooth Transition Vector AutoRegression (STVAR) with a single transition variable as in our framework. According to this test, we assume linearity under null hypothesis versus a nonlinear model with a logistic smooth transition component under alternative hypothesis. Let us assume a p-dimensional 2-regime approximate logistic STVAR model:

$$
\mathbf{X}_{t}=\Theta_{o}^{\prime} Y_{t}+\sum_{i=1}^{n} \boldsymbol{\Theta}_{i}^{\prime} \mathbf{Y}_{t} z_{t}^{i}+\varepsilon_{t}
$$

where $\mathbf{X}_{t}$ is the $(p \times 1)$ vector of endogenous variables, $\mathbf{Y}_{t}=\left[\mathbf{X}_{t-1}|\ldots| \mathbf{X}_{t-k}\right]$ is the 
$(k \times p+q)$ vector of exogenous variables which includes lagged variables $(k)$ and a vector of constants. The transition variable is $z_{t}$, while $\Theta_{0}$ and $\Theta_{i}$ are matrices of parameters. In our empirical assessment, we have $p=7$ as number of endogenous variables, $q=1$ as number of exogenous variables, and $k=5$ as number of lags. Under the null hypothesis of linearity, we assume $\mathbf{H}_{o}: \Theta_{i}=0 \forall i$. The Teräsvirta and Yang (2014) test features the following four steps:

1) We estimate the restricted model $\left(\mathbf{H}_{o}: \Theta_{i}=0 \forall i\right)$ by regressing $\mathbf{X}_{t}$ on $\mathbf{Y}_{t}$. We collect the residual $\tilde{\mathbf{E}}$ calculating the matrix for the residual sum of squares $R S S_{0}=\tilde{\mathbf{E}} \cdot \tilde{\mathbf{E}}$.

2) We run an auxiliary regression of $\tilde{\mathbf{E}}$ on $\left(\mathbf{Y}_{t}, \mathbf{Z}_{n}\right)$ where the subscript $n$ indicates the n-order Taylor expansion of the transition function. We save the residuals $\tilde{\boldsymbol{\Xi}}$ computing the matrix for the residual sum of squares $R S S_{1}=\tilde{\boldsymbol{\Xi}}^{\prime} \tilde{\boldsymbol{\Xi}}$.

3) We compute the test-statistic:

$$
L M=\operatorname{Ttr}\left[R S S_{0}^{-1}\left(R S S_{0}-R S S_{1}\right)\right]=T\left[p-\operatorname{tr}\left(R S S_{0}^{-1} R S S_{1}\right)\right]
$$

Under the null hypothesis, the test statistic is distributed as a $\chi^{2}$ with a number of degree of freedoms equals the number of restrictions, $p(k p+q)$. We compute two LM-type linearity tests fixing the value of the n-order of the Taylor expansion equal to $n=1$ and $n=3$ (as proposed by Luukkonen, Saikkonen, and Teräsvirta, 1988). In our estimation, $\mathrm{LM}=503.4$ and $\mathrm{LM}=1254.6$ when $n=1$ and $n=3$, respectively. The corresponding p-value in both tests is zero. In other words, our model presents non-linear dynamics.

\section{Appendix: Estimation of the Non-linear VARs}

Our STVAR model (1)-(4) is estimated via maximum likelihood. The log - likelihood function is as follows:

$$
\log L=\mathrm{const}-\frac{1}{2} \sum_{t=1}^{T} \log \left|\boldsymbol{\Omega}_{t}\right|-\frac{1}{2} \sum_{t=1}^{T} \varepsilon^{\prime}{ }_{t} \boldsymbol{\Omega}^{-1} \varepsilon_{t},
$$

where the vector of residuals $\varepsilon_{t}=X_{t}-\left(1-F\left(z_{t}\right)\right) \Pi_{N T} X_{t-1}-F\left(z_{t}\right) \Pi_{R} X_{t-1}$. Our purpose is to estimate the parameters $\Psi=\left\{\Omega_{R}, \Omega_{N T}, \Pi_{R}(L), \Pi_{N T}(L)\right\}$, where $\Pi_{j}(L)=$ $\left[\Pi_{j, 1}, \ldots, \Pi_{j, p}\right], j \in\{R, N T\}$.

Due to the high non-linearity of the model its estimation is problematic using standard optimisation procedures. Hence, as in Auberbach and Gorodnichenko (2012), we employ the procedure as described as follows.

Conditional on $\gamma, \Omega_{R}, \Omega_{N T}$, where $\gamma$ is the slope parameter calibrated as described in section 2 , the model is linear in $\Pi_{R}, \Pi_{N T}$. Hence, for a given guess on $\gamma, \Omega_{R}, \Omega_{N T}$, the coefficients $\Pi_{R}, \Pi_{N T}$ can be estimated by minimizing $\frac{1}{2} \sum_{t=1}^{T} \varepsilon_{t}^{\prime} \Omega^{-1} \varepsilon_{t}$. Hence, we can re-write the regressors as below. 
Let $\mathbf{W}_{t}=\left[F\left(z_{t}\right) \mathbf{X}_{t-1}\left(1-F\left(z_{t}\right)\right) \mathbf{X}_{t-1} \ldots F\left(z_{t}\right) \mathbf{X}_{t-p}\left(1-F\left(z_{t}\right)\right) \mathbf{X}_{t-p}\right]$ be the extended vector of regressors, and $\boldsymbol{\Pi}=\left[\boldsymbol{\Pi}_{R}(L) \boldsymbol{\Pi}_{N T}(L)\right]$. Consequently, we can write $\varepsilon_{t}=\mathbf{X}_{t}-\boldsymbol{\Pi}_{\mathbf{W}^{\prime}}{ }_{t}$. In this case, the objective function becomes:

$$
\frac{1}{2} \sum_{t=1}^{T}\left(\mathbf{X}_{t}-\boldsymbol{\Pi} \mathbf{W}_{t}^{\prime}\right)^{\prime} \boldsymbol{\Omega}_{t}^{-1}\left(\mathbf{X}_{t}-\boldsymbol{\Pi} \mathbf{W}_{t}^{\prime}\right)
$$

We can show that the first order condition with respect to $\Pi$ is given by:

$$
v e c \boldsymbol{\Pi}^{\prime}=\left(\sum_{t=1}^{T}\left[\boldsymbol{\Omega}_{t}^{-1} \otimes \mathbf{W}_{t}^{\prime} \mathbf{W}_{t}\right]\right)^{-1} \operatorname{vec}\left(\sum_{t=1}^{T} \mathbf{W}_{t}^{\prime} \mathbf{X}_{t} \boldsymbol{\Omega}_{t}^{-1}\right)
$$

We iterate this procedure over different sets of values for $\left\{\Omega_{R}, \Omega_{N T}\right\}$ (conditional on a given value for $\gamma$ ). For each set of values, $\Pi$ is obtained and the $\log L$ (7) is calculated. Due to the high non-linearity of the model in its parameters, we might get several local optima. Then, it is recommended to try different starting values of $\gamma$. To guarantee positive definiteness of the matrices $\Omega_{R}$ and $\Omega_{N T}$, we focus on the alternative vector of parameters $\Psi=\left\{\operatorname{chol}\left(\boldsymbol{\Omega}_{R}\right), \operatorname{chol}\left(\boldsymbol{\Omega}_{N T}\right), \boldsymbol{\Pi}_{R}(\mathrm{~L}), \boldsymbol{\Pi}_{N T}(L)\right\}$, where chol means the Cholesky decomposition.

We compute the confidence intervals using a Markov Chain Monte Carlo (MCMC) algorithm developed by Chernozhukov and Hong (2003) (CH hereafter). This methodology gives us both a global optimum and densities for the parameter estimates.

We implement the $\mathrm{CH}$ estimation via a Metropolis-Hastings algorithm. Given a starting value $\Psi^{0}$, the procedure constructs chains of length $N$ of the parameters of the estimated model following two steps:

Step 1: Draw a candidate vector of parameter values $\boldsymbol{\Theta}^{(n)}=\Psi^{(n)}+\psi^{(n)}$ for the chain's $n+1$ state, where $\Psi^{(n)}$ is the current state and $\psi^{(n)}$ is a vector of i.i.d. shocks drawn from $N\left(0, \Omega_{\Psi}\right)$, and $\boldsymbol{\Omega}_{\boldsymbol{\Psi}}$ is a diagonal matrix.

Step 2: Set the $n+1$ state of the chain $\Psi^{(n+1)}=\boldsymbol{\Theta}^{(n)}$ with probability $\min \left\{1, L\left(\boldsymbol{\Theta}^{(n)}\right) / L\left(\boldsymbol{\Psi}^{(n)}\right)\right\}$, where $L\left(\boldsymbol{\Theta}^{(n)}\right)$ is the value of the likelihood function conditional on the candidate vector of parameter values, and $L\left(\Psi^{(n)}\right)$ is the value of the likelihood function conditional on the current state of the chain. Otherwise, set $\Psi^{(n+1)}=\Psi^{(n)}$.

The starting value $\boldsymbol{\Theta}^{(0)}$ is calculated using the second-order Taylor approximation of the model described from (1) to (4) in the section 2, hence the model can be written as regressing $\mathbf{X}_{t}, \mathbf{X}_{t} z_{t}$, and $\mathbf{X}_{t} z_{t}^{2}$. We employ the residuals from this regression to fit the expression for the reduced-form time-varying variance-covariance matrix of the VAR (as explained in the main text) using maximum likelihood to estimate $\boldsymbol{\Omega}_{R}$ and $\boldsymbol{\Omega}_{N T}$.

We can construct $\Omega_{t}$, conditional on these estimates and given the calibration for $\gamma$. Conditional on $\boldsymbol{\Omega}_{t}$, we can compute the starting values for $\boldsymbol{\Pi}_{R}(L)$ and $\boldsymbol{\Pi}_{N T}(L)$ using equation (9). 
Given the calibration for the initial (diagonal matrix) $\Omega_{\Psi}$, a scale factor is adjusted to generate an acceptance rate close to 0.3 , the typical value for this computational methods as pointed out by Canova (2007). The estimation accounts for $N=50,000$ draws and we use the last $20 \%$ for inference.

As described by $\mathrm{CH}, \boldsymbol{\Psi}^{*}=\frac{1}{N} \sum_{t=1}^{T} \boldsymbol{\Psi}^{(n)}$ is consistent estimate of $\boldsymbol{\Psi}$ under standard regularity assumptions on maximum likelihood estimators. The covariance matrix of $\Psi$ is given by $V=\frac{1}{N} \sum_{t=1}^{T}\left(\Psi^{(n)}-\Psi^{*}\right)^{2}=\operatorname{var}\left(\boldsymbol{\Psi}^{(n)}\right)$, which is the variance of the estimates in the generated chain.

\section{E Appendix: Generalized Impulse Response Functions}

The Impulse Response Functions for the STVAR model are computed following the approach introduced by Koop, Pesaran, and Potter (1996) which propose an algorithm to calculate the Generalized Impulse Response Functions (GIRFs). The implementation of their procedure is composed of the following steps.

1) We construct the set of all possible histories $\boldsymbol{\Lambda}$ of length $p=12:\left\{\lambda_{i} \in \boldsymbol{\Lambda}\right\}$, where $\boldsymbol{\Lambda}$ contain $T-p+1$ histories $\lambda_{i}$ and $T$ is the sample size $(T=551)$.

2) We separate the set of all recessionary histories from that of all normal times histories. We calculate the transition variable $z_{\lambda_{i}}$ for each $\lambda_{i}$. If $z_{\lambda_{i}} \leq z^{*}=-0.95 \%$, then $\lambda_{i} \in \Lambda^{R}$, where $\Lambda^{R}$ refers to all recessionary histories; if $z_{\lambda_{i}}>z^{*}=-0.95 \%$, then $\lambda_{i} \in \Lambda^{N T}$, where $\Lambda^{N T}$ refers to all normal times histories.

3) We select at random one history $\lambda_{i}$ from the set $\Lambda^{R}$, taking $\hat{\Omega}_{\lambda_{i}}$ obtained as follows:

$$
\hat{\mathbf{\Omega}}_{\lambda_{i}}=F\left(z_{\lambda_{i}}\right) \hat{\boldsymbol{\Omega}}_{R}+\left(1-F\left(z_{\lambda_{i}}\right)\right) \hat{\mathbf{\Omega}}_{N T},
$$

where $z_{\lambda_{i}}$ is the transition variable computed for the selected history $\lambda_{i} . \hat{\Omega}_{R}$ and $\hat{\Omega}_{N T}$ are calculated from the generated MCMC chain of the parameter values during the estimation step. As in Koop, Pesaran, and Potter (1996), we consider the distribution of parameters rather than their mean values to allow for parameter uncertainty.

4) We estimate the variance-covariance matrix $\hat{\Omega}_{\lambda_{i}}$ using the Cholesky-decomposition:

$$
\hat{\Omega}_{\lambda_{i}}=\hat{\mathbf{C}}_{\lambda_{i}} \hat{\mathbf{C}}_{\lambda_{i}}^{\prime}
$$

we orthogonalize the estimated residuals to get the structural shocks as:

$$
\mathbf{e}_{\lambda_{i}}^{(j)}=\hat{\mathbf{C}}_{\lambda_{i}}^{-1} \hat{\varepsilon}
$$

5) From $\mathbf{e}_{\lambda_{i}}$ draw with replacement $h$ nine-dimensional shocks and get the vector of 
bootstrapped shocks

$$
\mathbf{e}_{\lambda_{i}}^{(j) *}=\left\{\mathbf{e}_{\lambda_{i, t}}^{*}, \mathbf{e} *_{\lambda_{i, t+1}}^{*}, \ldots, \mathbf{e} *_{\lambda_{i, t+h}}^{*}\right\}
$$

where $h$ is the number of horizons for the IRFs we compute.

6) We form another set of bootstrapped shocks which are equal to (13) except for the $k_{t h}$ shock in $\mathbf{e}_{\lambda_{i}}^{(j) *}$ which is the shock we perturb by a $\delta$ amount. We call the vector of bootstrapped perturbed shocks as $\mathbf{e}_{\lambda_{i}}^{(j)^{\delta}}$.

7) We transform back $\mathbf{e}_{\lambda_{i}}^{(j) *}$ and $\mathbf{e}_{\lambda_{i}}^{(j)^{\delta}}$ as follows:

$$
\hat{\varepsilon}_{\lambda_{i}}^{(j) *}=\hat{\mathbf{C}}_{\lambda_{i}} \mathbf{e}_{\lambda_{i}}^{(j) *}
$$

and

$$
\hat{\varepsilon}_{\lambda_{i}}^{(j)^{\delta}}=\hat{\mathbf{C}}_{\lambda_{i}} \mathbf{e}_{\lambda_{i}}^{(j)^{\delta}}
$$

8) We use (14) and (15) to simulate the evolution of $\mathbf{X}_{\lambda_{i}}^{(j) *}$ and $\mathbf{X}_{\lambda_{i}}^{(j) \delta}$ and we construct the $\operatorname{GIRF^{(j)}}\left(h, \delta, \lambda_{i}\right)$ as $\mathbf{X}_{\lambda_{i}}^{(j) *}-\mathbf{X}_{\lambda_{i}}^{(j) \delta}$.

9) Conditional on history $\lambda_{i}$, repeat for $j=1, \ldots, B$ vectors of bootstrapped residuals and get $\operatorname{GIRF}^{1}\left(h, \delta, \lambda_{i}\right), \operatorname{GIRF}^{2}\left(h, \delta, \lambda_{i}\right), \ldots, G I R F^{B}\left(h, \delta, \lambda_{i}\right)$. We set $B=500$.

10) We calculate the GIRF conditional on history $\lambda_{i}$ as:

$$
\hat{G I R F}^{(i)}\left(h, \delta, \lambda_{i}\right)=B^{-1} \sum_{j=1}^{B} G I R F^{(i, j)}\left(h, \delta, \lambda_{i}\right) .
$$

11) We repeat all previous steps for $i=1, \ldots, 500$ histories belonging to the set of recessionary histories, $\lambda_{i} \in \Lambda^{R}$, and we get $\operatorname{GIRF}^{(1, R)}\left(h, \delta, \lambda_{1, R}\right), \operatorname{GIRF}^{(2, R)}\left(h, \delta, \lambda_{2, R}\right), \ldots$, $G \hat{I R F}^{(500, R)}\left(h, \delta, \lambda_{500, R}\right)$ where the subscript $R$ means that we are conditioning upon recessionary histories.

12) We take the average and we get $\operatorname{GR}^{(R)}\left(h, \delta, \Lambda_{R}\right)$, which is the average GIRF under recessions.

13) We repeat all the previous steps from 3 to 12 for 500 histories belonging to the set of all normal times and we get $G \hat{I R F^{(N T)}}\left(h, \delta, \Lambda_{N T}\right)$.

14) We compute the $68 \%$ confidence bands for the IR by picking up for each horizon of each state, the $16 t h$ and $84 t h$ percentile of the densities $G \hat{I R F}^{([1: 500], R)}$ and $G \hat{I R F}{ }^{([1: 500], N T)}$. 


\section{References}

Gilchrist, S. and E. Zakrajšsek (2012). "Credit Spreads and Business Cycle Fluctuations". Econometrica, 102(4), pp. 1692-1720.

Hansen, B. (1999). "Testing for Linearity". Journal of Economic Surveys, 13(5), pp. 551574.

Koop, G., M. Pesaran, and S. Potter (1996). "Impulse Response Analysis in Nonlinear Multivariate Models". Journal of Econometrics, 74(1), pp. 119-148.

McCracken, M.W. and Ng (2016). "Fred-MD: A Monthly Database for Macroeconomic research". Journal of Business and Economic Statistics, 34(4), pp. 574-589. 


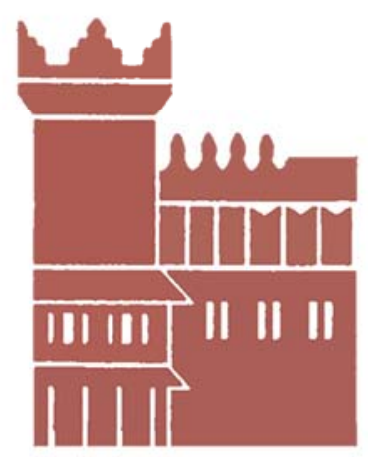

Alma Mater Studiorum - Università di Bologna DEPARTMENT OF ECONOMICS

Strada Maggiore 45

40125 Bologna - Italy

Tel. +39051 2092604

Fax +390512092664

http://www.dse.unibo.it 